\title{
Occurrence of Trihalomethanes in Chlorinated Waters from Different Sources Used for Urban Supply
}

\author{
Armindo Melo ${ }^{1, *}$, Catarina Mansilha ${ }^{2}$, Margarida Teixeira ${ }^{3,4}$, Isabel M.P.L.V.O. Ferreira1 \\ ${ }^{1}$ REQUIMTE/Department of Chemical Science, Food Science Laboratory and Hydrology, Faculty of Pharmacy, \\ University of Porto, Portugal \\ ${ }^{2}$ Department of Environmental Health, National Institute of Health Doctor Ricardo Jorge, Porto, Portugal \\ ${ }^{3}$ REQUIMTE, University of Porto, Porto, Portugal \\ ${ }^{4}$ Faculty of Science and Technology, University of Algarve, Faro, Portugal
}

Copyright (C) 2016 by authors, all rights reserved. Authors agree that this article remains permanently open access under the terms of the Creative Commons Attribution License 4.0 international License.

\begin{abstract}
Trihalomethanes (THMs) are one of the most common disinfection by-products formed by the reaction of chlorine and/or bromide with organic matter and/or bromide. Total THMs in chlorinated treated water are defined as the sum of the concentrations of chloroform (TCM), bromodichloromethane (BDCM), dibromochloromethane (DBCM), and bromoform (TBM). The monitoring of trihalomethanes THMs in distribution tap water collected in from five regions of Portugal, from North to South, in a total of 33 samples, during spring to summer season, is described. Solid phase microextraction coupled to gas chromatography and electron capture detector methodology was applied to determine whether THMs concentrations in urban water supply systems are is in agreement with European Regulations. It was found a great discrepancy in total THMs concentration values, with concentrations varying from 1.8-97.7 $\mu \mathrm{g} / \mathrm{L}$, although the results were below the European parametric value of $100 \mu \mathrm{g} / \mathrm{L}$. Regarding the Environmental Protection Agency regulations, however, only 97\% of samples fulfilled the established criterion of $80 \mu \mathrm{g} / \mathrm{L}$. and investigate if the individual compounds trihalomethanes content in was also investigated in order to determine if there is observed distribution tap water follows a common or a different THMs pattern in close geographical areas. In the geographical areas under study, mean values of concentrations measured revealed two different clusters: one including the three groups from the North geographical areas,
\end{abstract} with samples revealing a similar pattern ( $\mathrm{TCM}>\mathrm{BDCM}>\mathrm{DBCM}>\mathrm{TBM}$ ), and another including the two groups from South with a different THMs pattern ( $\mathrm{DBCM}>\mathrm{BDCM}>\mathrm{TCM}>\mathrm{TBM})$. A great degree of variation in the concentrations of THMs in tap water was observed, although the results the total THMs concentrations were below the European parametric value $(100 \mu \mathrm{g} / \mathrm{L})$. Mean results of samples grouped by five geographical areas revealed a similar pattern in samples collected from North and Centre TCM $>$ BDCM $>$ DBCM $>$ TBM, whereas samples from South presented a different pattern,
$\mathrm{DBCM}>\mathrm{BDCM}>\mathrm{TCM}>\mathrm{TBM}$. The origin of raw water (surface or groundwater) seems to influence this different pattern formation of brominated compounds.

Keywords Chlorinated Water, Disinfection By-products (DBPs), Trihalomethanes (THMs), Drinking Water Analysis

\section{Introduction}

The assurance of drinking-water quality is determinant for populational health and wellbeing. Disinfection is a critical part of the treatment procedure being fundamental to prevent waterborne infectious diseases.

The majority of Portuguese plants for supply of drinking water use chlorination, as disinfection strategy, to provide potable water. Chlorine is a powerful oxidizing agent that ensures inactivation of pathogenic microorganisms and control biofilm growth, thus a residual concentration throughout the distribution system, particularly at end points, is required. However, chlorine has the disadvantage of producing disinfection by-products (DBPs) due to reactions with naturally occurring organic matter in raw water $[1,2]$. Although there is a wide range of DBPs, of the trihalomethanes (THMs), specially chloroform (TCM), bromodichloromethane (BDCM), dibromochloromethane (DBCM) and bromoform (TBM), are the most common, and are generally considered as good indicators of chlorination by-products in drinking water [3, 4].

It is well kwon that the health risks from disinfection by-products are much less than the risks from consuming or using water that has not been disinfected, nevertheless the negative impact of THMs, even at low levels, on human health is a matter of concern [4].

Individual exposure to THMs from tap water can occur not only through ingestion, but also by inhalation of indoor air, largely due to volatilization from drinking-water, or 
dermal exposure during showering or bathing since TTHM through ingestion composed less than $10 \%$ of integrated internal dose $[5,6]$.

Numerous epidemiological studies have been directed to explore the correlations between chlorination by-products and incidence of human cancer, and more recently, with adverse reproductive outcomes [7, 8]. In 2011, Regina Grazuleviciene et al. found epidemiological evidence for a dose-response relationship between the THMs blood internal dose of pregnant women, exposed through drinking water by ingestion, showering and bathing, and child low birth weight found epidemiological evidence for a dose-response relationship between THM internal dose exposure and low birth weight [9]. Identical conclusions were achieved by Iszatt $\mathrm{N}$. et al. in 2014 suggesting that a high decrease in chloroform concentrations in tap water is associated with a statistically significant reduction in very low birth weight rates [10]. The World Health Organization also stated that Exposure exposure to BDCM from four areas: ingestion of drinking-water, inhalation of indoor air, inhalation and dermal exposure during showering or bathing, and ingestion of food, has been linked to increased risk for spontaneous abortion or stillbirth, implying a reevaluation of the guideline value for this compound as long as new data on possible reproductive effects become available [11].

There are also evidences that oral exposures to binary mixtures of chloroform and BDCM, DBCM or TBM would likely result in a significant increase of the level of unmetabolized chloroform in the blood, relatively to chloroform when administered alone. TBM and DBCM appear to persist in blood and tissues for longer periods of time when co-administered with chloroform [12].

Considering health outcomes from lifelong exposure and the limited information about the risks and uncertainties that arise from mixtures effects, efforts are currently made by water suppliers and legislators to maintain the concentrations of THMs as low as reasonably achievable without compromising the effectiveness of disinfection[6, 13, 14].

Due to the toxicity of these compounds, namely the potential health effects from long-term exposure in liver, kidney or central nervous system and increased risk of cancer, the National Primary Drinking Water Regulations from US Environmental Protection Agency [15] established a Maximum Contaminant Level (MCL) for total THM concentration at $80 \mu \mathrm{g} / \mathrm{L}$, as an annual average, with individual maximum contaminant level goals (MCLG) of zero for bromodichloromethane and bromoform, $60 \mu \mathrm{g} / \mathrm{L}$ for dibromochloromethane and $70 \mu \mathrm{g} / \mathrm{L}$ for chloroform. MCLG are non-enforceable health goals, based on the best available science to prevent potential health problems due to exposure over a lifetime, with an adequate margin of safety.

The European and Canadian regulations settled a limit of $100 \mu \mathrm{g} / \mathrm{L}$ for total trihalomethanes [16], although some European countries, such as Germany, Luxembourg and Sweden, have restricted THMs concentration to $50 \mu \mathrm{g} / \mathrm{L}$. Other state members such as Austria, Belgium and Italy have restricted even more these THMs concentrations to $30 \mu \mathrm{g} / \mathrm{L}$
[17].

The World Health Organization established more permissive individual guideline values: $300 \mu \mathrm{g} / \mathrm{l}$ for Chloroform, $\quad 100 \quad \mu \mathrm{g} / \mathrm{l}$ for Bromoform and Dibromochloromethane and $60 \quad \mu \mathrm{g} / \mathrm{l}$ for Bromodichloromethane. However, to account for additive toxicity, the sum of the ratio of each of the four levels of THMs to their individual guideline value should not exceed $1[7,18]$.

The THMs can be determined by different analytical techniques. The U.S. Environmental Protection Agency (EPA) has approved three methods for the analysis of THMs in drinking water. Method 502.2 uses purge and trap capillary column gas chromatography with photoionization and electrolytic conductivity detectors in series; Method 524.2 determines THMs using capillary column gas chromatography/mass spectrometry and Method 551.1 uses liquid-liquid extraction and gas chromatography with electron-capture detection (LLE/ECD) [19]. Monitoring of THMs in tap water used for human consumption is of great interest in order to assess consumer's exposure.

Until now, there have been only a few studies in Portugal to evaluate the risk of the consumers 'exposure to THMs through tap water. The main objectives of this work were: i) to monitorize trihalomethanes in distribution water from North to South of Portugal during spring to summer season, since by-product formation is directly related with disinfectant concentration and this is period where the weather is warmer and higher disinfection is needed; ii) to investigate if the trihalomethanes profile in distribution tap water follow a common pattern in close geographical areas.

\section{Materials and Methods}

\subsection{Sample Collection}

Thirty three samples were collected from North to South of Portugal during spring to summer season directly from the distribution system (see Figure 1). All samples were taken from water supply systems endpoints in a $40 \mathrm{~mL}$ amber vials completely filled to avoid any headspace and evaporation of compounds in the flasks, and were quenched immediately with sodium thiosulphate $(300 \mu \mathrm{l}$ of a $0.3 \mathrm{~g} / 1$ S2O 32 solution) to eliminate further formation of THMs. The samples were transported to the laboratory at $4^{\circ} \mathrm{C}$ and maintained at $4^{\circ} \mathrm{C}$ and away from light until extraction.

The sampling points of water were grouped into five zones (see Figure 1) located in the North (Z1, Z2 and Z3) and South of Portugal (Z4 and Z5). Portugal depends on both surface and groundwater sources for the domestic water supply. Depending on the region the main sources of water are rivers and underground aquifers, especially in North and dam reservoirs in South rivers and underground aquifers. The conventional water treatment plants in Portugal consist of pre-oxidation, coagulation, flocculation, decantation, filtration and final disinfection. 


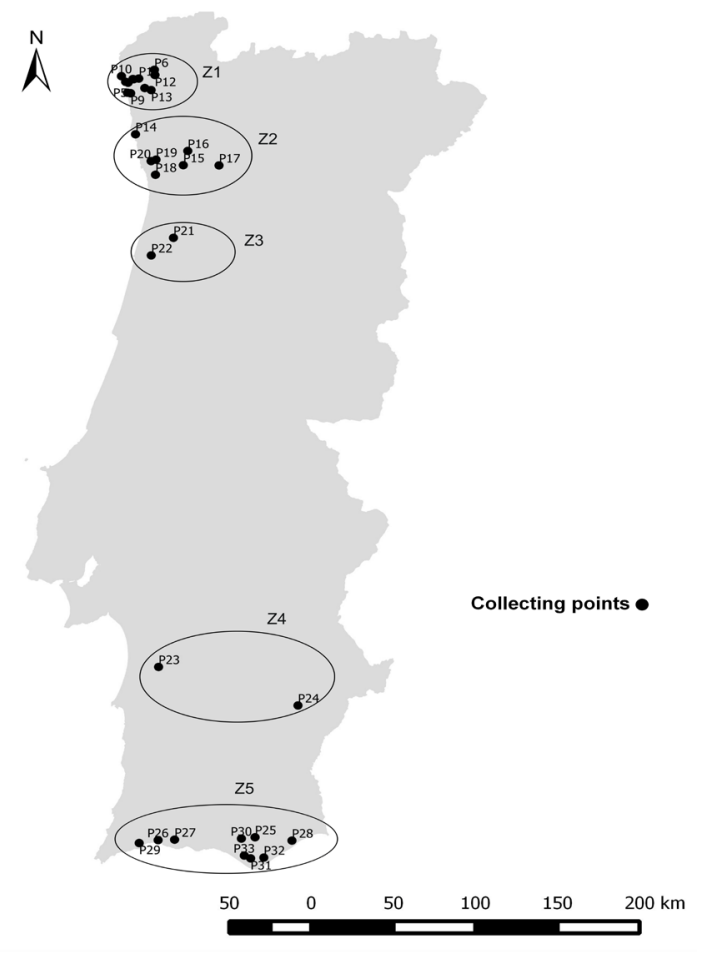

Figure 1. Map of Portugal showing the distribution of the 33 collecting points considered in the present study. Geographical areas studied: Z1"Minho", Z2 - "Grande Porto", Z3 - "Aveiro", Z4 - "Alentejo", Z5 "Algarve".

\subsection{Reagents and Analytical Methodology}

A commercially THMs mixture in methanol (chloroform (CAS. 66-65-3), bromodichloromethane (CAS. 75-27-4), dibromochloromethane (CAS. 124-48-1), bromoform (CAS. 75-25-2)) containing $100 \mathrm{ng} / \mu \mathrm{L}$ of each compound (EPA 551A Halogenated Volatiles Mix) was purchased from Dr. Ehrenstorfer. This mixture was handled in accordance with material safety data sheet. Intermediate standard solution of THMs with $1 \mathrm{mg} / \mathrm{L}$ was obtained by diluting the THMs mixture standard solution with ultrapure methanol (Merck). Stock calibration standard solutions, in the a range 5-100 $\mu \mathrm{g} / \mathrm{L}$, were thean prepared in $20 \mathrm{~mL}$ vials (from Supelco) for calibration by diluting the intermediate stock solution with deionized Milli-QTM water (Millipore, Bedford, MA, EUA) boiled for 4 hours to remove any volatile residue. ultrapure type I water directly into $20 \mathrm{~mL}$ vials (from Supelco). All standards were analyzed in triplicate. Screw-capped vials (20 $\mathrm{mL}$ ), sealed with teflon lined silicon septum were used for storing the standard solutions as well as for water samples.

The four trihalomethane species mentioned in the European regulation [16] (TCM, BDCM, DBCM, TBM) were determined, using an analytical methodology based on EPA Method 551.1, in a Varian CP-3800 gas chromatograph (GC) equipped with a $63 \mathrm{Ni}$ electron capture detector (ECD) and with an auto a CombiPAL autosampler injector AOC-5000 (CTC Analytics AG, Zwingen, Switzerland) with a SPME fiber assembly.injector AOC-5000. The analytical column was a Varian Factor Four VF-624ms, $30 \mathrm{~m}$ length,
$0.25 \mathrm{~mm}$ i.d. and $1.4 \mu \mathrm{m}$ thicknesses. The oven program temperature was as follows: initial temperature $60^{\circ} \mathrm{C}$, then was ramped at $9^{\circ} \mathrm{C} / \mathrm{min}$ to $150^{\circ} \mathrm{C}$ and, finally, increased at $25^{\circ} \mathrm{C} / \mathrm{min}$ to $250^{\circ} \mathrm{C}$. Injection port and detector temperatures were set at $260^{\circ} \mathrm{C}$ (splitless) and $300^{\circ} \mathrm{C}$, respectively.

The experimental conditions were established to obtain high efficiency in the extraction and analytical steps. Solid phase microextraction (SPME) methodology (SPME) was chosen instead of the liquid-liquid extraction procedure referred in EPA method, and was performed using $100 \mu \mathrm{m}$ Polydimethylsiloxane (PDMS) fibers supplied by Supelco. The Extraction parameters were optimized to achieve good sensitivity in the GC/ECD analysis.

Before each sample set was run a blank analysis was always performed in order to do a precondition of the PDMS SPME fiber, by exposing it for $10 \mathrm{~min}$ to the headspace of a vial containing $10 \mathrm{~mL}$ ultra-pure water. Subsequently, the fiber is inserted into the GC inlet and desorbed for $10 \mathrm{~min}$. Any desorbed chemicals were cleared from the GC column by maintaining the $\mathrm{GC}$ oven at high temperatures during this initial instrument preparation procedure. Sample analyses began by moving the active sample to the heated agitator station $\left(40^{\circ} \mathrm{C}\right)$ of CombiPAL. Following preincubation (5 $\mathrm{min})$ the SPME fiber is inserted into the vial headspace and samples were extracted for $10 \mathrm{~min}$ at $250 \mathrm{rpm}$. The extraction time of $10 \mathrm{~min}$ was selected to balance the need for maximum analyte extraction against adsorbing too much water vapor from the headspace. The fiber is then desorbed by insertion into the $\mathrm{GC}$ inlet $\left(260^{\circ} \mathrm{C}\right)$ for $10 \mathrm{~min}$ to ensure complete analyte desorption.

The method was validated mainly in accordance with the guidelines established by International Conference on Harmonization recommendations [20]. Calibration curves, with six calibration points $(5,15,25,50,75,100 \mu \mathrm{g} / \mathrm{L}$ of each analyte), were constructed using the least squares linear regression model, plotting the peak area ratios of the different compounds versus the concentration of each analyte under study.

\section{Results and Discussion}

In water samples analysis, high correlation coefficients were obtained in calibration lines for all THMs. Limits of detection were $1.7 \mu \mathrm{g} / \mathrm{L}$ and coefficients of variation ranged from $10 \%$ to $25 \%$.

Calibration graphs showed good linear response for the concentration range of target compounds with correlation coefficient (r) higher than 0.99. Limits of quantification (LOQ) were $1.7 \mu \mathrm{g} / \mathrm{L}$. Specificity and selectivity were evaluated by comparing the chromatograms of matrix-blank samples (different samples of ultrapure water and glass bottled mineral water) and an aqueous solution of the analytes at concentrations near the limit of quantification. No significant interference has been detected at the retention times. 
Table 1. THMs in chlorinated water from public supply in Portugal (expressed as $\mu \mathrm{g} / \mathrm{mL}$ )

\begin{tabular}{|c|c|c|c|c|c|}
\hline Sample Code & $\mathrm{TCM}$ & TBM & $\mathrm{BDCM}$ & DBCM & Total THM \\
\hline 1 & 71.6 & 7.1 & 14.6 & 4.4 & 97.7 \\
\hline 2 & 31.5 & n.d & 7.4 & 3.4 & 42.3 \\
\hline 3 & 35.9 & n.d & 6.6 & n.d & 42.5 \\
\hline 4 & 5.3 & n.d & 4.4 & 4.9 & 14.6 \\
\hline 5 & 20.8 & n.d & 4.1 & n.d & 24.9 \\
\hline 6 & 44.7 & n.d & 6.8 & n.d & 51.5 \\
\hline 7 & 10.8 & n.d & 4.0 & 4.8 & 19.5 \\
\hline 8 & 5.8 & 3.2 & n.d & 3.2 & 12.3 \\
\hline 9 & 10.8 & n.d & 3.1 & n.d & 14.0 \\
\hline 10 & 2.3 & 5.2 & 4.9 & 9.1 & 21.5 \\
\hline 11 & 26.04 & n.d & 5.24 & n.d & 31.3 \\
\hline 12 & 18.16 & n.d & 10.35 & 4.95 & 33.5 \\
\hline 13 & 14.33 & n.d & 8.18 & 5.82 & 28.3 \\
\hline 14 & 48.09 & n.d & 4.32 & 4.72 & 57.1 \\
\hline 15 & 45.48 & n.d & 2.42 & 11.24 & 59.1 \\
\hline 16 & 32.61 & 2.49 & 8.42 & 12.18 & 43.5 \\
\hline 17 & 1.77 & n.d & n.d & n.d & 1.77 \\
\hline 18 & 42.42 & n.d & 2.72 & 12.60 & 57.7 \\
\hline 19 & 38.44 & n.d & 2.6 & 11.90 & 52.9 \\
\hline 20 & 42.30 & n.d & 3.1 & 13.94 & 59.3 \\
\hline 21 & 55.97 & n.d & 1.61 & 5.07 & 62.6 \\
\hline 22 & 49.03 & n.d & 2.59 & 12.01 & 63.6 \\
\hline 23 & n.d & 7.31 & 2.06 & 6.85 & 16.2 \\
\hline 24 & 1.97 & n.d & n.d & n.d & 1.97 \\
\hline 25 & 16.48 & n.d & 17.65 & 15.62 & 49.8 \\
\hline 26 & 7.16 & 10.33 & 15.48 & 23.94 & 56,9 \\
\hline 27 & 4.98 & 9.94 & 12.52 & 22.11 & 49.6 \\
\hline 28 & 16.08 & n.d & 16.24 & 14.70 & 47.0 \\
\hline 29 & 3.97 & 9.82 & 10.77 & 19.02 & 43.6 \\
\hline 30 & 12.34 & 3.62 & 13.88 & 12.79 & 42.6 \\
\hline 31 & 10.95 & n.d & 12.33 & 12.30 & 35.6 \\
\hline 32 & 9.17 & n.d & 11.03 & 11.42 & 31.6 \\
\hline 33 & 11.4 & 3.1 & 10.96 & 10.37 & 35.8 \\
\hline
\end{tabular}


Precision and accuracy were also determined. To evaluate intermediate precision, or inter-assay precision, $n=6$ replicates were performed in independent days at 3 different levels $(5.0,50.0$ and $100.0 \mu \mathrm{g} / \mathrm{L})$ presenting acceptable values ranging from $17.9 \%$ for BDCM at LOQ level to $2.9 \%$ for $\mathrm{DBCM}$ at the higher level. Accuracy, expressed as absolute bias, was inferior to $5 \%$ of the accepted true value for all compounds, except at LOQ level where greater values, varying from 5.0 to $19.6 \%$, were observed.

In order to transfer the validated method into laboratory working routine, its performance is evaluated annually through the participation in an interlaboratory study for THMs analysis provided by LGC Standards Proficiency Testing, Aquacheck Sample 6A. Collaborative trials allow to estimate accuracy and to evaluate the possible bias of an analytical method. To assess the performance of the method $z$-scores were provided, being satisfactory $(|z| \leq 2)$ for each analyte. Z-scores are indicators that compare the difference between the reported result of the laboratory and the assigned value (bias), with a standard error.

Results from the survey of 33 water samples to evaluate the content of TCM, TBM, BDCM, and DBCM, collected from North to South of Portugal are presented in Table 1. Chloroform was the most frequently detected VOC in samples from drinking-water supply systems with concentrations varied from 1.77 to $71.6 \mu \mathrm{g} / \mathrm{L}$. The concentrations of TBM in water samples ranged from not detected to $10.33 \mu \mathrm{g} / \mathrm{L}$, the BDCM varied between not detected and $17.65 \mu \mathrm{g} / \mathrm{L}$, and the DBCM varied between not detected and $23.94 \mu \mathrm{g} / \mathrm{L}$.

Several factors contribute to the contents of THMs in chlorinated water which justifies the great degree of variation in the measured concentrations, namely naturally occurring organic matter concentration, chlorine dose, contact time, water $\mathrm{pH}$ and temperature, length of the distribution network and bromide ion concentration.

The Total THMs concentration was in agreement with drinking water quality standards in $100 \%$ of the results [6], being below the European parametric value $(100 \mu \mathrm{g} / \mathrm{L})$, as well as in accordance with the criteria set by WHO based on a fractionation approach. However, regarding other European countries such as Germany, Luxembourg and Sweden regulations, only $69.7 \%$ of water samples complied with the limit of $50 \mu \mathrm{g} / \mathrm{L}$. EPA enforceable regulation criterion has been fulfilled by $97 \%$ of water samples that complied with the maximum contaminant level (MCL) of 80 $\mu \mathrm{g} / \mathrm{L}$. Nevertheless, when individual values are analyzed, all samples presented concentrations of BDCM and TBM above zero, which is the maximum contaminant level goal for these two compounds. High THMs values usually occur at points in the distribution system with the longest residence time or water age, such as reservoirs, oversized pipes and network dead ends [9].

Figure 2 presents the mean results of samples grouped by five main geographical areas. Samples collected from North (clusted as Z1, Z2 and Z3) presented a similar pattern. TCM was the most abundant THM, followed by BDCM, and
DBCM. TBM was very low or not detected. Samples from South, where water supply is mostly from dam reservoirs, presented a different pattern; the most abundant THM was DBCM, followed by BDCM and TCM. TBM concentration in some samples was approximately $10 \mu \mathrm{g} / \mathrm{L}$.

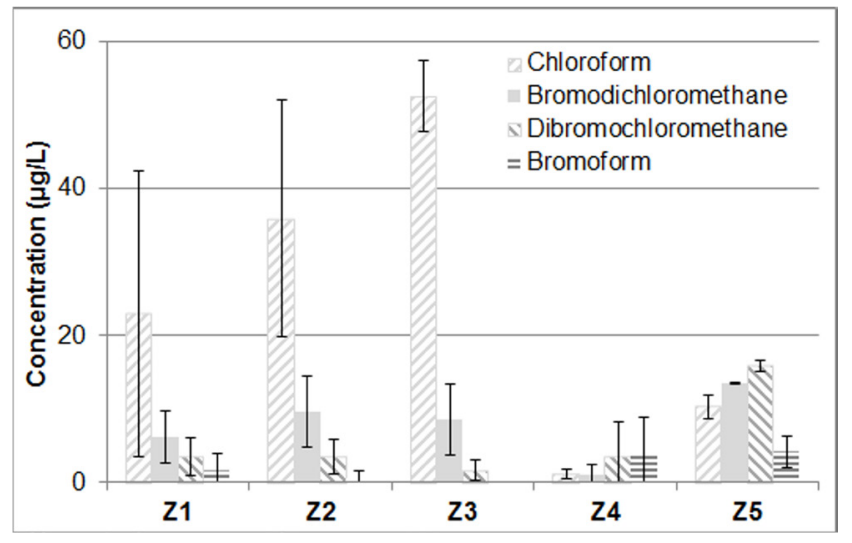

Figure 2. Mean values of THM contained in samples grouped by geographical areas: Z1 ( $\mathrm{n}=13), \mathrm{Z2}(\mathrm{n}=7), \mathrm{Z3}(\mathrm{n}=2), \mathrm{Z4}(\mathrm{n}=2)$ and $\mathrm{Z5}(\mathrm{n}=9)$.

According to literature, TCMchloroform tends to be the THM present in the greatest concentration in chlorinated waters, especially when originated from raw water sources with high organic matter contents $[6,8]$. This assumption was not observed in water samples from the South of Portugal.

In the presence of bromides, brominated THMs are formed preferentially and chloroform concentrations decrease proportionally. [7]. TBM and DBCM are found mainly in water that originally came from surface sources, such as rivers and lakes. Springs, deep drilled wells or underground aquifers, more abundant in North, usually contain very little of the substances that react with chlorine to form these chemicals; therefore, well and spring water is less likely a source of TBM and DBCM than water from a reservoir (artificial lake) [21]. It is also known that the amount of TBM and DBCM in drinking water can change considerably from day to day, depending on the source, temperature, amount of plant material in the water, amount of chlorine added, and a variety of other factors. Brominated THMs may pose greater risk than chloroform TCM to human health because they have been found to be more toxic than TCMchloroform in toxicological assays [10]. Water systems that use surface water or ground water under the direct influence of surface water and use conventional filtration treatment are required to remove specified percentages of organic materials that may react with disinfectants to form disinfection byproducts, prior to disinfection. Other control strategies include modification of disinfection practices in a manner that still provides adequate protection against pathogens. Therefore, the European regulations for THM should be reviewed to account for different patterns that can be found in chlorinated water and different health risks posed by each one of the four THMs.

The results from the present work highlight the importance of THMs monitoring, especially when individual 
contaminant levels are analyzed, for an accurate environmental health risk assessment. More studies are needed to understand the influence of the water source, its original nature and treatment processes on THMs formation.

\section{Conclusions}

This study with a simplified sample collection protocol can be useful in quantifying exposure to these potentially harmful chemicals and in helping to support larger epidemiological field studies. Where THMs were quantified by solid phase microextraction coupled to gas chromatography and electron capture detector in chlorinated drinking water from Portugal, to determine whether it was observed that urban water supply is were in agreement with European Regulation, however taking in account other European countries guidelines this value pass to $69.7 \%$ of water samples complied with the limit of $50 \mu \mathrm{g} / \mathrm{L}$. It was also demonstrated that according source and type water and investigate if the THMs content in distribution tap water follows a common pattern in close geographical areas. A similar THMs pattern (TCM $>$ BDCM $>$ DBCM $>$ TBM) was observed in water supply from North, and different from South $(\mathrm{DBCM}>\mathrm{BDCM}>\mathrm{TCM}>\mathrm{TBM})$, emphasizing that brominated THMs may pose greater risk than TCM to human health because they have been found to be more toxic than TCM in toxicological assays.

A major challenge for water suppliers is how to control and limit the risks from pathogens and disinfection byproducts. It is important to provide protection from pathogens while simultaneously minimizing health risks to the population from disinfection byproducts.

\section{Acknowledgements}

This work received financial support from the European Union (FEDER funds POCI/01/0145/FEDER/007265) and National Funds (FCT/MEC, Fundação para a Ciência e Tecnologia and Ministério da Educação e Ciência) under the Partnership Agreement PT2020 UID/QUI/50006/2013. One of the authors (A. Melo) wishes to thank the Fundação Ciência Tecnologia grant SFRH/BPD/86898/2012.

\section{REFERENCES}

[1] U. Iriarte, J. I. Alvarez-Uriarte, R. Lopez-Fonseca,J. R. Gonzalez-Velasco, Trihalomethane formation in ozonated and chlorinated surface water. Environmental Chemistry Letters. Vol. 1, No. 1, 57-61, 2003.

[2] M. Basu, S. K. Gupta, G. Singh,U. Mukhopadhyay, Multi-route risk assessment from trihalomethanes in drinking water supplies. Environmental Monitoring and Assessment. Vol. 178, No. 1-4, 121-134, 2011.
[3] World Health Organization, Water Safety in Distribution Systems. World Health Organization, Geneva, Switzerland, 2014.

[4] Health Service Executive (HSE) and Environmental Protection Agency (EPA), Joint Position Statement, Trihalomethanes in Drinking Water. Environmental Protection Agency: Washington, USA, 2011.

[5] J. R. Nuckols, D. L. Ashley, C. Lyu, S. M. Gordon, A. F. Hinckley,P. Singer, Influence of tap water quality and household water use activities on indoor air and internal dose levels of trihalomethanes. Environmental Health Perspectives. Vol. 113, No. 7, 863-870, 2005.

[6] C. M. Villanueva, K. P. Cantor, J. O. Grimalt, G. Castano-Vinyals, N. Malats, D. Silverman, A. Tardon, R. Garcia-Closas, C. Serra, A. Carrato, N. Rothman, F. X. Real, M. Dosemeci,M. Kogevinas, Assessment of lifetime exposure to trihalomethanes through different routes. Occupational and Environmental Medicine. Vol. 63 No. 4, 273-277, 2006

[7] World Health Organization, Trihalomethanes in drinking water: Background document for development of WHO guidelines for drinking water quality. World Health Organization, Geneva, Switzerland, 2004.

[8] M. J. Nieuwenhuijsen, M. B. Toledano, N. E. Eaton, J. Fawell,P. Elliott, Chlorination disinfection byproducts in water and their association with adverse reproductive outcomes: a review. Occupational and Environmental Medicine. Vol. 57, No. 2, 73-85, 2000.

[9] R. Grazuleviciene, M. J. Nieuwenhuijsen, J. Vencloviene, M. Kostopoulou-Karadanelli, S. W. Krasner, A. Danileviciute, G. Balcius,V. Kapustinskiene, Individual exposures to drinking water trihalomethanes, low birth weight and small for gestational age risk: a prospective Kaunas cohort study. Environmental Health. Vol. 10, No. 32, 2011.

[10] [10] N. N. Iszatt, M. J. Nieuwenhuijsen, J. E. Bennett,M. B. Toledano, Trihalomethanes in public drinking water and stillbirth and low birth weight rates: an intervention study. Environment International. Vol. 73, 434-439, 2014.

[11] [World Health Organization, Guidelines for drinking-water quality. World Health Organization, Geneva, Switzerland,20 11.

[12] M. L. da Silva, G. Charest-Tardif, K. Krishnan,R. Tardif, Influence of oral administration of a quaternary mixture of trihalomethanes on their blood kinetics in the rat. Toxicology Letters. Vol. 106, No. 1, 49-57, 1999.

[13] L. A. Salas, M. Bustamante, J. R. Gonzalez, E. Gracia-Lavedan, V. Moreno, M. Kogevinas, C. M. Villanueva, DNA methylation levels and long-term trihalomethane exposure in drinking water: an epigenome-wide association study. Epigenetics. Vol. 10 No. 7, 650-61, 2015.

[14] S. Chowdhury,K. Hall, Human health risk assessment from exposure to trihalomethanes in Canadian cities. Environment International. Vol. 36 No. 5, 453-60, 2010.

[15] Environmental Protection Agency, National Primary Drinking Water Regulations: Stage 2 Disinfetants and Disinfection Byproducts Rule, Environmental Protection Agency, Washington, USA. 2006. 
[16] European Union, Council Directive 98/83/EC on the quality of water intended for human consumption, European Union. 1998.

[17] T. Karanfil, S. W. Krasner, P. Westerhoff,Y. F. Xie, Recent Advances in Disinfection By-Product Formation, Occurrence, Control, Health Effects, and Regulations, in Disinfection by-Products in Drinking Water: Occurrence, Formation, Health Effects, and Control. American Chemical Society. Vol. 995, 2-19, 2008.

[18] World Health Organization., Guidelines for drinking-water quality. 4th ed., World Health Organization, Geneva, Switzerland, 2011.

[19] Environmental Protection Agency, Drinking Water Methods for Chemical Contaminants. Analytical Methods Approved for Drinking Water Compliance Monitoring under the Disinfection Byproduct Rules, Environmental Protection Agency, Washington USA. 2014.

[20] International Conference on Harmonisation (ICH), Harmonised tripartite guideline, Validation of analytical procedures: text and methodology Q2 (R1). Geneva Switzerland. 2005.

[21] Agency for Toxic Substances and Disease Registry, Public Health Statement for Bromoform and Dibromochloromethan e. Agency for Toxic Substances and Disease Registry Division of Toxicology and Human Health Sciences, Atlanta, USA, 2005. 